\title{
ÉCFRASIS DE IDA Y VUELTA: MONÓLOGO DRAMÁTICO Y CULTURALISMO EN «TRÉBOL», DE RUBÉN DARÍO
}

\author{
Alejandro Jacobo EgEA \\ Universidad de Alicante
}

\section{Resumen}

De los numerosos homenajes que Rubén Darío compuso a lo largo de su trayectoria poética, uno de los que más subversivamente ha sido tratado por la crítica es «Trébol», palabra en la que aparecen agrupados tres sonetos donde el poeta nicaragüense realizó su particular veneración a las figuras de Velázquez y Góngora. En este trabajo se lleva a cabo un estudio sobre la técnica y el procedimiento de composición poética utilizada en estos textos, así como su análisis estilístico, para finalizar con el replanteamiento de una cuestión polémica: el posible gongorismo de Rubén Darío en dichos sonetos.

Palabras clave: Rubén Darío, «Trébol», poesía de la experiencia, culturalismo, écfrasis, gongorismo.

\begin{abstract}
From the abundant tributes that Rubén Darío wrote during his poetic career, one of the most subversively treated by Dario's critics is the one named «Trébol», a word in which three sonnets are showed grouped together where the Nicaraguan poet paid his particular tribute to Velázquez and Góngora. In this article, a study on the technique and poetic composition of these texts is fulfilled, as well as a stylistic analysis of them, to conclude with a rethinking of a controversial issue: the potential gongorism of Rubén Darío in these sonnets.
\end{abstract}

Keywords: Rubén Darío, «Trébol», poetry of experience, culturalism, ekphrasis, gongorism. 


\section{Introducción}

En 1861 el poeta Charles Baudelaire publicó la segunda edición de Las flores del mal. Abría dicha edición un poema titulado «Proyecto de Epílogo», donde leemos en sus dos últimos versos: «porque de cada cosa la quintaesencia extraje / tú me diste tu barro y [yo] lo convertí en oro» ${ }^{1}$. Independientemente del sentido original que tienen estos versos —en ellos, el anhelo del poeta por la idealización del amor permite alcanzar la unión de los contrarios mediante la alquimia espiritual-, podemos establecer una analogía y señalar que esa es precisamente la labor de todo poeta, es decir, en el acto de creación poética, el poeta toma distintos elementos de la realidad —el barro-, y, gracias a la capacidad psicológica de la mímesis (gr. $\mu$ í lic $_{\text {) }}$, convierte dichos elementos en oro, en belleza estética.

Para la historia de la poesía hispánica — y sin dejar de lado esta metáfora baudelairiana-, eso fue precisamente lo que el Modernismo consiguió con Rubén Darío como máximo representante, ya que este movimiento artístico y literario surgió como revulsivo de las estéticas romántica y realista, cuya presencia en las poéticas europeas había perdido fuerza hacia mitad del siglo XIX (Fernández, 1989: 78 ss.; 1990: 48 ss.).

En este sentido, con Cantos de vida y esperanza (1905) asistimos a la plenitud del movimiento, donde Darío sintetizó todo lo que fue como poeta ${ }^{2}$ y donde hallamos asimismo versos con una marcada exaltación del espíritu hispánico, junto a poemas que suponen varios homenajes. ${ }^{3}$ A uno de esos homenajes está dedicado nuestro estudio. Nos referimos a «Trébol», palabra donde aparecen agrupados tres sonetos recopilados en la tercera sección de Cantos de vida y esperanza, titulada: «Otros poemas».

Previamente a su aparición en Cantos de vida y esperanza, estos tres sonetos se publicaron el 15 de junio de 1899 en las páginas de la revista La

1. «Car j'ai de chaque chose extrait la quintessence, / Tu m'as donné ta boue et j'en ai fait de l'or.» (Baudelaire, 2012: 46)

2. Efectivamente, con Cantos de vida y esperanza Darío culminó la representación de su universo poético, cuyas líneas podemos sintetizar como sigue: a) la esteticista, cuyas notas más características son la selectividad y la aristocracia, la suntuosidad y el refinamiento, y el exotismo y el cosmopolitismo; b) la del sensualismo, entendido como conocimiento y goce del mundo a través de los sentidos (Rossi de Fiori, I., et al., 2004: 18).

3. Poemas como: «Salutación del optimista», «Cyrano en España»o «A Roosevelt», entre otros, incluidos en la primera sección de la obra («Cantos de vida y esperanza»), cuyas composiciones obedecieron claramente a la amenaza de lo anglosajón y del Imperialismo de los EEUU que dominaba en la época (Salinas, 1975: 217 ss.; Ruiz Barrionuevo, 2002: 96-99; Rovira, 2004: 27). Entre los homenajes, podemos destacar: «Un soneto a cervantes», «Soneto autumnal al Marqués de Bradomín», «Letanía de Nuestro Señor Don Quijote», «A Goya», o «Trébol». 
Ilustración Española y Americana. Dicha publicación obedeció a un estímulo inmediato que es de sobra conocido: en 1899 se celebró en Madrid el tercer centenario del nacimiento del pintor Diego de Velázquez. Rubén Darío, que iba camino a la tercera «Exposición Universal» de París, cuya celebración iba a ser en 1900 (Carilla, 1961: 242; Rovira, 2004: 210; 2011: 36-37; Roses, 2007: 281), pasó por la capital de España y visitó el Museo del Prado, donde se exponían los cuadros del pintor homenajeado. Visita que Darío reflejó en su crónica «La fiesta de Velázquez», publicada en La Nación el mismo 15 de junio de 1899 —al igual que los sonetos en la otra revista_, y recogida hoy en la obra España contemporánea, del mismo Darío. En dicha crónica, y tras denunciar la poca acogida que tuvo el centenario del pintor sevillano en Madrid, el poeta señala, aunque vagamente, el motivo que le impulsó a escribir los tres sonetos: «Es en 1622, Velázquez va a visitar El Escorial, y para ello parte para la Corte con buenas recomendaciones y con el encargo de hacer el retrato de Góngora» (Darío, 1998: 204).

Como sabemos, el retrato al que alude Darío es el famoso retrato velazqueño a Luis de Góngora, que va a ser fundamental a la hora de comprender, al menos, los dos primeros sonetos. En el primero de ellos, titulado: «De D. Luis de Argote y Góngora a D. Diego de Silva Velázquez» (Darío, 2011: 442$443)^{4}$, Darío habla a través del poeta cordobés, o mejor dicho, a través de la figura retratada sobre el lienzo. El segundo soneto, «De D. Diego de Silva Velázquez a D. Luis de Góngora y Argote» (2011: 443), es la respuesta del pintor sevillano a las palabras de elogio recibidas por Góngora, en un monólogo que el pintor nos brinda mientras observa la figura retratada. El ahora textual remite por tanto al momento en que está componiendo la pintura. Por último, el tercer soneto (2011: 443-444), sin título, presenta el homenaje que hace Rubén Darío a los dos artistas del Barroco, cuyo ahora textual nos sitúa en la época del poeta modernista (Entrambasaguas, 1975: 189).

\section{La originalidad de Darío: técnica de composición poética en «Trébol»}

Resulta un hecho innegable que en toda obra literaria de poesía lírica predomine el enfoque subjetivo. Sin embargo, desde mediados del siglo XIX, a las definiciones tradicionales de la lírica como género que expresa la experiencia subjetiva del poeta, muchas veces se ha objetado «que el sujeto o hablante

4. Como hacen notar algunos críticos como Dámaso Alonso (1970: 540), José Manuel Martos (1998: 174, n. 5) o José Carlos Rovira (2004: 212), el orden de los apellidos del poeta cordobés que Darío publicó primeramente es correcto (Argote y Góngora, y no Góngora y Argote, como lo conocemos hoy en día). 
lírico no corresponde exactamente al yo del autor, sino a una suerte de personaje en el que aquél se desdobla» (García Berrio y Hernández Fernández, 2004: 279). Ello no debe resultarnos nada extraño, pues es bien sabido que, dentro de los múltiples rasgos de la ruptura modernista con respecto a la norma literaria romántica y realista-naturalista, uno de ellos sea el de la superación del intimismo confesional directo -intimismo que se refiere a la presencia directa del «yo» subjetivo y sentimental del poeta en las composiciones (Carnero, 2002: 20)—, cuya obsolescencia supuso la aparición en la poesía del monólogo dramático y del culturalismo ${ }^{5}$, característica fundamental de la poesía moderna. Por tanto, uno de los argumentos que más peso han tenido para caracterizar a la poesía contemporánea es el de señalar que los poetas modernos - como Mallarmé, Verlaine, Baudelaire, y por supuesto Rubén Darío en el ámbito hispánico- manifiestan en sus composiciones un sujeto despersonalizado absolutamente independiente de su propio yo personal.

Con relación a esto último que acabamos de apuntar, en los últimos años la crítica dariana ha señalado que a partir de Cantos de vida y esperanza el yo personal de Darío se desintegra y despersonaliza, sin que por ello deje de dominar en los textos poéticos. Es decir, hay una metamorfosis poética en Cantos de vida y esperanza sin que haya rompimiento con el pasado poético de Darío y, sobre todo, encontramos en dicha obra una nueva forma de hacer poesía en su poética personal a través del procedimiento del enmascaramiento o de incluso la ficción del yo enunciador del poema (Anderson Imbert, 1967; Paz, 1999; Rovira, 2004; 2016; Bernabé, 2007). Rasgos todos ellos, como venimos diciendo, que son herederos de la poesía romántica inglesa — Browning, Yeats—, de la escuela poética parnasiana francesa —Verlaine, Mallarmé—, y, sobre todo, del Simbolismo francés — Baudelaire, Moréas-.

5. El culturalismo tiene dos acepciones: la primera se refiere «al empleo de [...] referencias filosóficas, artísticas, literarias o de cualquier otro tipo - aunque siempre relacionadas con el saber- dentro de la obra literaria propia» (Platas Tasende, 2004: 193). La segunda acepción hace alusión al procedimiento poético mediante el cual aparece en el poema una «mención directa u oblicua de personajes, situaciones, frases — ha señalado José Olivio Jiménez - , que el poeta toma de la historia de la cultura y que por su cuenta recrea [...] para hacerlos portavoces de sus propias intuiciones» (Jiménez, 1972: 378). Para no confundir ambas acepciones, preferimos designar a la primera de ellas con el nombre de intertextualidad, y a la segunda culturalismo propiamente dicho. En § 2.1. nos referimos al culturalismo en su segunda acepción, es decir, como técnica de composición poética. Para el uso del culturalismo en tanto que técnica utilizada para la inclusión de referencias artísticas en la obra de arte, vid. el $\S 4$ de nuestro artículo. 


\subsection{Monólogo dramático y culturalismo en "Trébol»}

Según lo dicho hasta aquí, en «Trébol» apreciamos que Rubén Darío somete las relaciones entre el Arte y la vida y las convierte en un complicado juego de espejos poéticos, consistente en la necesidad de separar al poeta de los personajes que hablan a través de los poemas —Velázquez y Góngora, en los dos primeros- Así, la distinción entre poeta —o autor-y personaje poético —o hablante lírico- puede justificarse a partir del procedimiento poético que utilizó Darío al componer estos sonetos. Nos referimos a que estos sonetos pueden enmarcarse acertadamente dentro de la denominada poesía de la experiencia o culturalista, en tanto que modo de composición poética que supone una alternativa al discurso de ese intimismo confesional post-romántico, como venimos diciendo. No nos detendremos en explicar lo que ha supuesto para la historia de la poesía moderna la etiqueta de poesía de la experiencia; un marbete que el crítico Robert Langbaum utilizó por primera vez en 1957 cuando publicó su estudio La poesía de la experiencia: el monólogo dramático en la tradición literaria moderna.

El término «experiencia» ciertamente es muy ambiguo y puede llevarnos a confusión. Con frecuencia se tiende a pensar que se refiere a la experiencia subjetiva, íntima, del poeta. No obstante, la poesía de la experiencia se refiere más bien al procedimiento poético según el cual el poema crea en sí mismo una experiencia, que obviamente no es la experiencia personal del poeta. Con ello, la intención es la de someter al lector a la experiencia primigenia que da origen al poema.

En el caso de los dos primeros sonetos de «Trébol», esa experiencia se crea en el diálogo -ficticio, por supuesto- entre Velázquez y Góngora. Ficticio porque no existió, y si existió no fue exactamente así. Para el tercer soneto Darío nos proporciona esa experiencia al mostrarnos con su homenaje los elementos necesarios para reconstruir objetivamente el proceso poético y llegar así a la comprensión última de todo el conjunto (Cullell, 2010: 75).

Por lo tanto, la idea fundamental es la de recrear una experiencia dentro del marco poético que nos brinda «Trébol», cuyo motivo fue, recordemos, la celebración del tercer centenario del nacimiento del pintor sevillano.

Ahora bien, ¿mediante qué procedimiento consigue Darío recrear esa experiencia en los sonetos de «Trébol»? Mediante lo que Langbaum denominó el monólogo dramático, que consiste en "conceder la voz poética a un personaje, o a un objeto personificado, cuyo discurso se expresa mediante la primera persona gramatical con el fin de presentar una experiencia identificable existencial o psicológicamente - $\mathrm{o}$ ambas a la vez — con la propia experiencia del autor» (Neira y Pérez Bazo, 2002: 94-95). Además, el poeta nicaragüense 
ha elegido como interlocutores a dos artistas del Siglo de Oro, e introduce asimismo elementos culturales -intertextuales - en los sonetos ${ }^{6}$, lo que nos lleva a considerar que nos hallamos también ante poemas culturalistas.

En este sentido, el culturalismo también es un procedimiento poético, un monólogo dramático, que, como ha especificado Guillermo Carnero,

permite hablar del yo sin mencionarlo, y referirse del mismo modo a las situaciones existenciales de la vida cotidiana, por el procedimiento de expresar lo uno y lo otro por analogía. El autor designa entonces a un personaje histórico, literario o representado en una obra de arte, cuando quiere manifestar que se encuentra en situación semejante a la suya; o bien designa a una obra literaria o artística cuando entiende que éstas significan algo idéntico o semejante a lo que quiere significar de sí mismo» (Carnero, 2008: 70).

Entiéndase entonces que en los dos primeros sonetos Rubén Darío se dice por la personalidad interpuesta de los personajes analógicos que actúan como hablantes líricos. Con ello, si bien hay casos de monólogo dramático antes del «Trébol» de Darío en la tradición lírica hispánica ${ }^{7}$, no es menos cierto que estos sonetos darianos son posiblemente, sino el primer caso de poesía culturalista escrita en lengua española ${ }^{8}$, sí de los primeros ejemplos.

En el primer soneto el yo poético —o hablante lírico- es el yo de Luis de Góngora, pero, como acertadamente ha señalado Joaquín Martos, no se refiere a su persona, sino al retrato, al objeto artístico (Martos, 1998: 175), de tal suerte que quien nos habla — quien habla a Velázquez— en ese primer soneto es el rostro retratado de Luis de Góngora. ${ }^{9}$ Por consiguiente, la «estructura profunda textual» o macroestructura —información subyacente que se encuentra en el texto considerado como globalidad (Van Dijk, 1972: 6, 130 ss.) —, la oración dominante que extraemos de la lectura de este primer

6. Vid. supra, n. 5 .

7. Gil de Biedma ya identificó el monólogo dramático en las Canciones de Espronceda (Gil de Biedma, 2010: 751). En Darío también hay ejemplos de dicho procedimiento antes de su «Trébol», vid., por ejemplo, «Coloquio de los Centauros».

8. Tradicionalmente se viene considerando en las historias y estudios de literatura española contemporánea que el culturalismo se inicia en España con la publicación de Desolación de la quimera (1962), de Luis Cernuda; procedimiento que excesivamente utilizaron poco después los llamados poetas novísimos o Generación de 1970.

9. Se establece de esta manera la relación entre poesía y pintura —ut pictura, pœsis- que Góngora había enunciado en su soneto «Al Conde de Villamediana, celebrando el gusto que tuvo en diamantes, pinturas y caballos». Así, al referirse a las pinturas que el Conde tenía en sus aposentos, el poeta dice: "afecta mudo voces, y parlero / silencio en sus vocales tintas miente» (Góngora, 1992: 110), es decir, que algunos cuadros parecen hablar, y sus colores son tan expresivos que hacen falsos sus silencios. La crítica reciente (Martos, 1998: 175) señala que los versos de Góngora dieron a Darío la idea de que el personaje retratado por Velázquez pareciera como si hablase. 
soneto sería la siguiente: yo, retrato del sujeto del retrato recuerdo ese día de 1622 en que tú me pintaste (Martos, 1998: 175). No obstante, en el segundo soneto, Velázquez interpela a su creación pictórica — porque es el retrato el que le ha hablado_-, no a la figura histórica, al Góngora histórico. Estamos, por tanto, ante un diálogo del pintor con su pintura; ante un logrado monólogo dramático culturalista de Rubén Darío, cuya «estructura profunda textual» sería: yo, artista del retrato, dialogo conmigo mismo ante mi creación [el retrato] sobre lo que me parece tu figura como poeta. En el tercer soneto no hay desdoblamiento en ningún personaje, sino una unión de las composiciones anteriores. Darío realiza aquí su particular homenaje y se identifica con estas dos figuras del pasado artístico-cultural español.

\subsection{Del lienzo y de los versos: sobre la Écfrasis en «Trébol»}

Hablamos a continuación de la fuente artístico-textual principal en torno a la cual se sustentan los sonetos, que no es otra que el retrato realizado por Velázquez a Góngora. Nos hallamos, pues, ante un caso de écfrasis poética, figura retórica de pensamiento que consiste en «la descripción de una obra artística por medio del lenguaje» (Platas Tasende, 2004: 235). Pero en «Trébol» no se nos describe ninguna obra, sino que esta —el retrato-cobra vida, aunque, eso sí, se nos muestren además rasgos de la personalidad de ambos artistas, por así decirlo. Con lo cual, debemos ampliar el concepto de écfrasis.

Según estudia Mayoral (1994: 187-190), esta figura retórica se complementa con otras. En nuestro caso, encontramos somatopeya - ficción del cuerpo en realidades incorpóreas-, como sucede en el primer soneto, en el que como ya hemos comentado, quien habla es la imagen de la entidad que aparece en el retrato; pero a su vez hallamos patopeya o referencia a los aspectos y pasiones, así como caracterismo de Velázquez y Góngora, expresado en los sonetos metonímicamente mediante la dicotomía Luz (Velázquez) / Voz (Góngora), verdadero pilar sobre el que se sustenta «Trébol» (Martos, 1998: 175).

En cuanto al sistema de representación ecfrástica, el siguiente diagrama ${ }^{10}$ expone la posible relación entre poeta, obra y destinatarios que se da en los sonetos de «Trébol»:

10. El diagrama que presentamos a continuación es una variación del que reproduce Luis Fernando García Martínez en su obra: La ékfrasis en la poesía contemporánea española: de Ángel González a Encarnación Pisonero, Madrid, Devenir Ensayo, 2011, p. 20. 


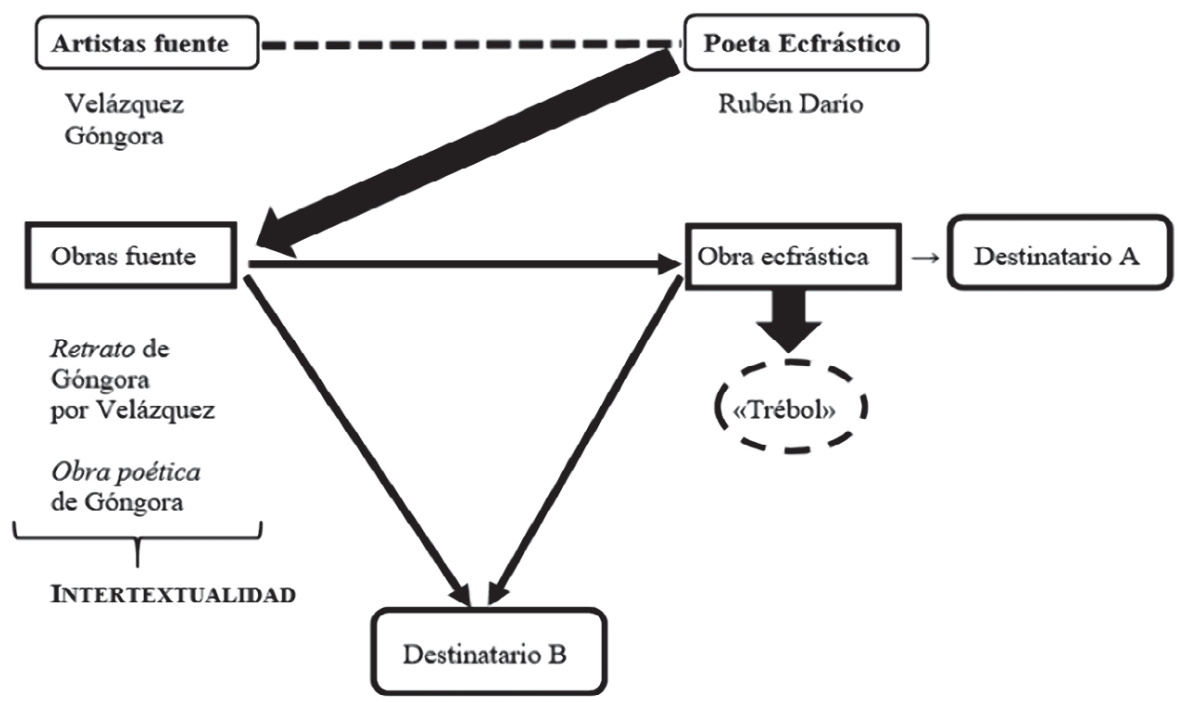

Diagrama I. Representación ecfrástica de «Trébol».

Como se puede observar, la relación que existe entre el poeta ecfrástico Rubén Darío- y los artistas fuente - Velázquez y Góngora- es unidireccional, puesto que el poeta conoce, al menos en parte, la evolución artística del pintor y el poeta cordobés, bien sea por biografías o estudios críticos. Recordemos que Darío había consultado algunos estudios sobre el pintor - como los de Madrazo, Lefort, Beruete-, según nos dice en la crónica a la que antes hemos aludido. No obstante, la obra que más llamó su atención fue Anales de la vida y obras de Diego Silva Velázquez, escrito con ayuda de nuevos documentos, de Gregorio Cruzada Villaamil, publicada en 1895; obra de donde extrajo el dato del encargo del retrato (Quintián, 1974: 162-163; Rovira, 2004: 211). Desconocemos no obstante si Darío había consultado alguna biografía sobre Góngora, aunque dudamos de que circulase alguna por la época en que escribió estos sonetos. Sí conocía, no obstante, parte de su obra, así como la de otros autores clásicos del Siglo de Oro.

Por otro lado, la relación entre Darío con las obras fuente - el retrato y la poesía de Góngora - constituye para nosotros el pilar fundamental de la écfrasis poética en «Trébol», pues dichas fuentes son su estímulo inmediato para componer los poemas, sobre todo, el retrato, leitmotiv de los dos primeros sonetos. En este sentido, el caso que nos ocupa es muy interesante, puesto que Darío compone los sonetos a partir de un conjunto de obras (el retrato 
velazqueño, aunque también alude a composiciones gongorinas, como se verá al señalar los elementos intertextuales más abajo).

Asimismo, tenemos la relación entre las obras fuente y «Trébol», que es la obra ecfrástica, determinada por el destinatario: los lectores. De esta manera, el lector A, que solo conoce «Trébol» —obra ecfrástica—, se encuentra con la dificultad de no conocer los elementos intertextuales y culturales que se hallan escondidos entre los versos. No obstante, el lector tipo B, que tiene acceso y conoce las obras fuente, puede disfrutar con mayor intensidad de la obra ecfrástica, según la competencia cultural que posea.

\section{Mirando a través de la penumbra: análisis de «Trébol»}

Hechas las anteriores consideraciones, una vez situados en el contexto en el que surgió la obra y explicado el procedimiento de composición poética que emplea Darío, vamos a realizar a continuación el comentario de los tres sonetos de acuerdo con la estructura de rasgos y fenómenos estilísticos aislados - o estilemas - atendiendo a los niveles de descripción lingüística, no sin antes hablar del título general que Darío dio a los poemas.

El DRAE '01 define la palabra «Trébol» de la siguiente manera: «Planta herbácea anual [...] de unos $20 \mathrm{~cm}$ de altura, con tallos vellosos, que arraigan de trecho en trecho, hojas casi redondas, pecioladas de tres en tres, flores blancas o moradas en cabezuelas apretadas, y fruto en vainillas con semillas menudas, que es espontánea en España y se cultiva como planta forrajera muy estimada.» Por tanto, el significado resulta claro para nosotros: "Trébol» funciona de manera simbólica al remitir a un concepto cuya idea es la perfección —recordemos la simbología del número 3- Tenemos, pues, tres sonetos, tres voces poéticas y tres personas. Además, la palabra alude también a una composición cerrada y perfecta desde el punto de vista de la construcción, como es el caso del soneto (Martos, 1998: 173). Así, nos hallamos ante tres sonetos que se ciñen al esquema tradicional —en sendos sonetos hay dos cuartetos y dos tercetos- Los versos de los dos primeros sonetos son endecasílabos consonantes y la rima que utiliza Darío en ambos es la misma: ABBA ABBA CDC CDC. No obstante, los versos del tercer soneto son alejandrinos de 14 sílabas, cuya rima es un tanto peculiar: el primer cuarteto es cruzado (ABAB) y el segundo es abrazado (ABBA), los dos tercetos muestran la misma rima $(\mathrm{CCD})^{11}$.

11. No deja de resultar curioso que cuando Darío utiliza como interlocutores a Góngora y a Velázquez componga los dos primeros sonetos a la manera convencional, y cuando 
Por lo que se refiere a los endecasílabos de los dos primeros sonetos, cabe decir que, según el acento rítmico, hallamos distintos tipos: enfático (acentos en $1^{\mathrm{a}} / 6^{\mathrm{a}} / 10$ sílabas, v. 2 , $\mathrm{I}^{12}$ : «ser en la eternidad sol sin poniente»); melódico (acentos en $3^{\mathrm{a}} / 6^{\mathrm{a}}$ y $10^{\mathrm{a}}$ sílabas, v. 8, I: «Y el Olvido lamenta su amargura»; v. 2, II: «al venir hacia mí ipor qué suspiras?»; v. 7, II: «y con nueva pasión que les inspiras»); un ejemplo de endecasílabo a la francesa (acento en $4^{a}$ sílaba sobre palabra aguda, en $8^{\text {a }}$ y $10^{\text {a }}$; v. 13, I: «con la alma luz, de tu pincel el juego»); sobre este último verso señalado, destacar el uso del artículo determinante en su forma femenina «la» delante de «alma»; licencia poética de Darío para que se produzca la sinalefa y poder construir correctamente el endecasílabo; sin embargo, en el verso 14 («el alma duplicó de la faz mía») sí emplea el artículo en su forma masculina, ya que de producirse la sinalefa el verso sería decasílabo. En cuanto al tercer soneto, nos encontramos con versos alejandrinos de 14 sílabas en su forma tradicional (divididos en dos hemistiquios de 7 sílabas cada uno). Con todo, Darío, como otros modernistas, experimenta con el alejandrino para romper con la monotonía del ritmo, y nos regala un verso magistral: «Aquí bronce corintio y allá mármol de Jonia» (v.9, III). La lectura del primer hemistiquio sería hasta «corintio», pero como hay sinalefa, se forma un hemistiquio que forzosamente tiene 9 sílabas («allá» es palabra aguda, y por eso se le suma una sílaba al cómputo silábico). Así, tenemos 9 sílabas del primer hemistiquio, más las 5 del segundo, en total 14 .

Importantes para la ruptura del ritmo y los efectos fonoacústicos son los encabalgamientos que aparecen. Por un lado, hallamos encabalgamiento abrupto - cuando el sintagma dividido termina antes de que finalice el verso siguiente- en los vv. 5-6 del primer soneto: «de España está sobre la veste obscura / tu nombre», y también encabalgamiento suave — cuando la segunda parte del sintagma dividido ocupa todo el verso siguiente-: «se alza al azul cual una / jaula de ruiseñores labrada en oro fino» (vv. 6-7, III). Asimismo, encontramos casos de aliteración tanto vocálica como consonántica. En cuanto a la primera: «ya el misterioso son del noble coro» (v. 5, II), donde la acentuación sobre la vocal cerrada /o/ transmite cierta sensación simbólica de intriga. Casos de aliteración consonántica: «rompe la Envidia el fatigado diente» (v. 7, I). Note el lector en este verso la fuerte carga simbólico-sentimental de las consonantes nasales, cuyo posible significado vendría dado por el hecho

aparece su voz en el tercer soneto lo componga al más puro estilo modernista (Mejías Alonso, 1985: 245-247).

12. Señalamos en lo sucesivo para nuestro análisis el número de versos, así como el número del soneto al que hagamos alusión en números romanos. Los sonetos de «Trébol» pueden consultarse en el Anexo I de nuestro trabajo. 
de que el sentimiento de la envidia se manifiesta unido al de la rabia, cuya manifestación física es la de apretar los dientes, de ahí que cuando la persona siente envidia parece como si se le fueran a romper los dientes - rompimiento que nos insinúan las dos primeras nasales, bilabiales y oclusivas ambas $/ \mathrm{m} /$ - También hay aliteración en este otro ejemplo: «jugando de la luz con la armonía, / con la alma luz, de tu pincel el juego» (vv. 12-13, I), donde la consonante lateral $/ \mathrm{l} / \mathrm{da}$ la sensación de que la claridad — luz del retrato, pero también la luz que designa metonímicamente el ingenio del pintor- fluye y se extiende con el paso de los siglos.

De acuerdo con el orden de los mecanismos morfosintácticos, abundan en los textos tanto la sustantivación, sobre todo los sustantivos abstractos («gloria», «eternidad», «España», «Envidia», «Olvido», «amistad», «alma», «Fama», «Fortuna»), como la adjetivación («fina», «noble», «misterioso», «grotescas», «celestes», «sutiles», etc.), lo que dota a los textos de mayor ornamentación, y con ello, de mayor complejidad. Los verbos de los dos primeros sonetos aparecen en presente, mostrando un diálogo de tú a tú, de cara a cara, de manera que se entrevé en el diálogo como si Velázquez y Góngora fueran amigos ${ }^{13}$.

Por otro lado, son muy frecuentes en los textos los hipérbatos: «de España está sobre la veste obscura / tu nombre» (vv. 5-6, I), es decir, tu nombre está sobre el vestido oscuro de España. Es este un verso cuya interpretación ha suscitado mucha polémica. Por ejemplo, autores como Dámaso Alonso (1970: 542) o Quintián (1974: 164-165) ven en él una posible alusión al desastre colonial de 1898 y las nefastas consecuencias que tuvo para España la pérdida de las últimas colonias. No obstante, nosotros proponemos una interpretación diferente, menos rebuscada y más sensata: si quien habla a través de estos versos es la imagen del retrato de Góngora, entonces el ahora textual del soneto no puede referirse a los tiempos en que Darío lo compuso, sino a la época en que Velázquez pintó dicho retrato, que fue, como dijimos, en 1622. Como sabemos, en 1621 subió al poder Felipe IV, y con las gestiones económicas de este monarca comenzó la verdadera decadencia española; gestiones que harían perder a España la hegemonía mundial a finales del siglo XVII, la

13. Como sabemos, Velázquez no fue coetáneo de Góngora, y, como señala Carilla (1961: 243), es casi imposible que lo tratase antes de 1622, ya que fue en ese año cuando el artista llegó a Madrid y pintó el retrato del poeta. Relación de amistad, por tanto, imaginada por el propio Darío, ya que de haber querido reflejar en su diálogo una relación de amistad, esta habría sido la de Góngora y El Greco, a quien el poeta cordobés dedicó el soneto «Inscripción para el sepulcro de Dominico Greco» (Góngora, 1992: 219). No olvidemos en este sentido que el motivo de composición de los sonetos darianos fue la conmemoración del tercer centenario del nacimiento de Velázquez. 
cual pasaría a manos de Francia. El sentido del verso queda claro: el nombre de Velázquez — su ingenio y arte- está por encima del ambiente hostil y decadente que asola al Impero español. Otros hipérbatos: «rompe la Envidia el fatigado diente» (v. 7, I); «Ya el misterioso son del noble coro/ calma el Centauro sus grotescas iras» (vv. 5-6, II); «en los celestes parques al Cisne gongorino / deshoja sus sutiles margaritas la Luna» (vv. 3-4, III); mecanismos tan propios en la poesía dariana con su búsqueda del preciosismo formal al complicar la lectura; se acerca de esta manera al culteranismo practicado no solo por Góngora, sino por otros poetas egregios del XVII español y novohispano (Carilla, 1962).

Hay también paralelismo: «Alma de oro, fina voz de oro» (v. 1, II); «Yo en equívoco altar, tú en sacro fuego» $(v .9, \mathrm{I})^{14}$, donde el hablante lírico señala que el alma del poeta reverbera la pintura en ese instante mediante el símbolo de la luz. Encontramos también paronomasia en las palabras («oro», "coro», «decoro») del primer cuarteto del segundo soneto, o en «castillo» y «camino», en el verso 5 del tercer soneto.

Entre las distintas figuras retóricas de amplificación, cabe destacar el oxímoron conceptual en el verso 2 del primer soneto: «sol sin poniente»; también hallamos perífrasis, que le sirve al hablante lírico en el soneto I para expresar su admiración por el pintor: «fénix de viva luz, fénix ardiente / diamante parangón de la pintura» (vv. 3-4). En cuanto a la comparación: «Tu castillo, Velázquez, se eleva en el camino / del Arte como torre que de águilas es cuna, y tu castillo, Góngora, se alza al azul cual una / jaula de ruiseñores labrada en oro fino» (vv. 4-7, III). En la primera compara a Velázquez con un señero castillo por su posición principal en la pintura española del Barroco (Quintián, 1974: 168), y así se iguala con un castillo que es «como bronce corintio»al que le corresponden las rosas, es decir, la gloria en el panteón de insignes artistas. En la segunda, compara a Góngora también con un castillo, imaginándole «cual una jaula de ruiseñores», al que llama «mármol de Jonia» y al que le asigna los claveles, que simbolizan el popularismo andaluz (Entrambasaguas,

14. Es este otro de los versos cuya interpretación ha causado controversia. Entrambasaguas (1975: 191-192) y Quintián (1974: 164-165) han dado dos posibles interpretaciones: la primera es que Darío conocía el prestigio de Velázquez y el olvido por parte de los poetas de la obra de Góngora; la segunda puede referirse al hecho de que Góngora se ordenase equivocadamente sacerdote, aunque de ser posible esta segunda interpretación, según piensa Entrambasaguas, lo más probable es que Darío «no trató más que de dar la sensación [...] de que el hábito de sacerdote no era el más propio para el autor de tantos desenfadados poemas como Góngora escribió, que, incluso sus coetáneos, le criticaron» (Entrambasaguas, 1975: 192). Nosotros preferimos decantarnos por la primera interpretación. 
1975: 190). Por último, asindeton o parataxis en los dos primeros sonetos, para agilizar el discurso poético, y también hay un caso de polisíndeton muy marcado en los dos tercetos del tercer soneto, mediante la utilización del nexo copulativo «y», lo que provoca cierto efecto de lentitud al texto.

Por lo que respecta al plano léxico-semántico, cabe decir que léxico empleado por Darío es culto, seleccionado cuidadosamente en las tres composiciones. No tardamos en advertir que es un léxico propio de la poesía del siglo de Oro, en homenaje a Góngora, sí, pero también al mejor Quevedo, Lope o Villamediana.

Aclarado esto último, encontramos los siguientes tropos empleados por el poeta modernista: sinécdoque o metonimia: «Alma de oro, fina voz de oro» (v. 1, II), donde la palabra «voz» se refiere a la voz poética de Góngora, no a la voz de su persona física. (v. 3). Una voz, un ingenio, que pronto alcanzará la fama que merece. Hay también casos de prosopopeya o personificación: «y el Olvido lamenta su amargura» (v. 8, I); «A Teócrito y a Poussin la Fama dote» (v. 9, II), así como abundancia de metáforas: «y tu castillo, Góngora, se alza al azul» (vv. 6-7, III), donde «azul» se emplea metafóricamente como el cielo. La fama de Góngora va poco a poco en ascenso continuo, en alza. Su obra («castillo»), aunque ahora esté encerrada, es bella como los ruiseñores y pronto ascenderá... poco le quedaba, pues Darío se da cuenta de lo importante que es la poesía de Góngora, antes que los poetas del 27, quienes, por cierto, no fueron los primeros en rescatarla del olvido ${ }^{15}$. Por último, destacar los símbolos utilizados en los tres sonetos («oro», «luz», «águilas», «laurel», «cisne», «ruiseñores»; «rosas», «claveles»), así como la alusión a personajes de la mitología: Fénix, Centauro, Hipogrifo, Polifemo, las nueve musas, el Pegaso divino, etc., y de la literatura y el arte: Teócrito de Siracusa, poeta bucólico autor de los Idilios, y Nicolás Poussin, pintor francés barroco, ambos citados en el verso 9 del segundo soneto.

\section{Intertextualidad y Gongorismo dariano en «Trébol»}

Queda por último hablar de los elementos intertextuales ${ }^{16}$ que aparecen en los poemas de «Trébol»—algunos de ellos ya comentados-. Para no de-

15. Contrariamente a lo que se piensa, y como se ha demostrado, a Góngora no lo 'redescubrieron' o rescataron del olvido nuestros mayores del 27 , sino que hayamos referencias a su ingenio y a su obra mucho antes. La nómina de autores que hicieron alusión al vate cordobés no es corta; entre estos podemos citar a Verlaine, Moréas, Hugo, Gourdmont, Tailhade, Manuel y Antonio Machado, Clarín, Manuel Reina, Juan Ramón Jiménez, Valle-Inclán y Rubén Darío (Alarcón Sierra, 2002).

16. Como sabemos, la intertextualidad tiene que ver con lo que en términos tradicionales se llama influencias, préstamos o plagios, y también como una negación de textos 
morarnos más, señalaremos a continuación aquellos elementos de «Trébol» referidos a la obra poética de Góngora.

La primera alusión a la obra de este aparece en el verso 6 del segundo soneto, y se refiere al Centauro, ser mitológico al que Darío ya había dedicado su «Coloquio de los centauros», incluido en Prosas profanas, y que en este soneto posiblemente se refiera a la metáfora utilizada por Góngora al comienzo de su Soledad segunda, como ha sugerido José Carlos Rovira (2004: 212), donde el Centauro es como el Océano, que mezcla su agua salobre con la dulce del río: «Centauro ya espumoso el Ocëano, / medio mar, medio ría» (Góngora, 1994: 421). Angélica y Medoro (v. 8, II) hace alusión a los personajes que protagonizan el romance caballeresco gongorino del mismo nombre. Por otro lado, «Polifemo» (v. 14, II) se refiere, como el lector sabe, al Cíclope que protagoniza junto a Galatea la obra de Góngora Fábula de Polifemo y Galatea, publicada en 1613. En el tercer soneto hallamos una referencia explícita a la conocida metáfora de «pisar» estrellas (v. 1, III), que Darío extrae, como sabemos, del verso de Góngora al comienzo de su Soledad primera: «en campos de zafiro pace estrellas» (Góngora, 1994: 197). ${ }^{17} \mathrm{El}$ «Cisne gongorino» (v. 3, III) es un motivo que Góngora frecuentó en sus poemas ${ }^{18}$, como se puede observar en estos versos de la silva XIII de la ya citada Fábula de Polifemo y Galatea: «Si roca de cristal no es Neptuno, / Pavón de Venus es, cisne de Juno» (Góngora, 2010: 159).

Señaladas las referencias intertextuales gongorinas, cabe decir que la inclusión de estas en los sonetos de Darío ha suscitado no poca polémica, ya que algunos críticos quisieron ver en estas composiciones una imitación o copia del estilo poético de Góngora. Algo sobre lo que nos gustaría recalcar para finalizar con nuestro trabajo.

anteriores, al distorsionar el autor frecuentemente los temas o significados originarios que dieron otros autores. Para la ampliación y conocimiento del concepto de intertextualidad y sus aplicaciones al ámbito de lo literario, vid. especialmente Martínez Fernández (2001).

17. Dámaso Alonso criticó duramente la utilización de esta metáfora gongorina por parte de Darío. No obstante, y como demostró Emilio Carilla, dicha metáfora fue utilizada por poetas contemporáneos a Góngora —-Lope de Vega, Quevedo, Medrano, Tirso, Bocángel, Pedro de Oña, Sigüenza y Góngora, Domínguez Camargo, Espinosa Medrano, etc.- y aun por poetas del siglo Xx —-Miguel Hernández y Pablo Neruda- (Carilla, 1962). Por nuestra parte, nos gustaría señalar un ejemplo más de esta metáfora en un soneto de Quevedo, que Emilio Carilla no presenta en el trabajo citado; nos referimos al verso 5 del soneto "Retrato de Lisi que traía en una sortija», en el que leemos: «traigo el campo que pacen estrellado» (Quevedo, 2005: 251).

18. Ese motivo también aparece en sonetos de Góngora como: «A una dama muy blanca, vestida de verde» (Góngora, 1992: 306) o en letrillas satíricas como «Ánsares de Menga» (Góngora, 1986: 309-310). 
Es sabido que la atracción de Darío por Luis de Góngora proviene de la tradición francesa (Carilla, 1961: 240; Rovira, 2016: 330) ${ }^{19}$, si bien es cierto que, como explica en su Autobiografía, Darío había leído la obra del poeta cordobés $^{20}$, posiblemente a través de la Primera parte de la colección de Poetas líricos de los siglos XVI y XVII, editada en 1854 por Rivadeneyra (Roses, 2007: 277).

Así, tras una explicación más o menos coherente y convincente de los tres sonetos, Dámaso Alonso concluyó con que no había en ellos una lectura profunda por parte de Darío de la obra poética de Góngora, y que asimismo dichos versos reflejaban falta de conocimiento de las peculiaridades sintácticas y metafóricas gongorinas, además de un sentido de manifiesto crítico y de profecía, para sentenciar que es «inútil buscar influencias o puntos de contacto en el resto de la obra de Rubén Darío. La poesía de éste no se parece en nada a la de Góngora.» (Alonso, 1970: 544) ${ }^{21}$. El prejuicio de don Dámaso no le dejó ver más allá de lo que hoy en día es un hecho incuestionable: no toda complicación o excentricidad formal en poesía es achacable a la influencia de Góngora. Es decir, el hecho de que hallemos en las composiciones darianas recursos propios del culteranismo y de que haya referencias explícitas a algunas obras de Góngora no quiere decir que Darío esté tratando de imitar al poeta cordobés.

Asimismo, como señala Carilla, «no siempre lo que aparece como homenaje o mención a Góngora es gongorismo» (1961: 239). En este sentido,

19. Conocida es la divertida escena relatada por el propio Darío en su Autobiografía: «Me habían dicho que Moréas sabía español. No sabía ni una sola palabra. Ni él ni Verlaine, aunque anunciaron ambos, en los primeros tiempos de la revista La Plume, que publicarían una versión de La vida es sueño, de Calderón de la Barca. Siendo así como Verlaine solía pronunciar, con marcadísimo acento, estos versos de Góngora: "A batallas de amor campo de plumas"; Moréas, con su gran voz sonora, exclamaba: "No hay mal que por bien no venga...". O bien: en cuanto me veía: “¡Viva don Luis de Góngora y Argote!"» (Darío, 1990: 72).

20. «Mis frecuentaciones en la capital de mi patria eran con gente de intelecto, de saber y de experiencia, y por ellos conseguí que se me diese empleo en la Biblioteca Nacional. Allí pasé largos meses leyendo todo lo posible y, entre todas las cosas que leí, ¡ horrendo referens!, fueron todas las introducciones de la Biblioteca de Autores Españoles de Rivadeneyra y las principales obras de casi todos los clásicos de nuestra lengua» (Darío, 1990: 21)

21. Muchos han sido los autores que han dedicado estudios a la comparación entre Góngora y Darío, entre los que destacamos, aparte de los ya referidos en nuestras páginas: Senabre (1967), Forcadas (1972 y 1976), y Petriconi (1968). Nosotros rebatiremos principalmente las ideas críticas de Dámaso Alonso sobre estos sonetos darianos, pues en parte, los críticos que han trabajado negativamente sobre estos sonetos que comentamos parten de sus argumentos. 
si hablamos de influencia gongorina, esta puede manifestarse a través de dos vías: en primer lugar, mediante evocaciones o recreaciones evidentes. En segundo lugar, mediante la manera gongorina de concebir la lengua poética, cuyo propósito es otorgar a esta la máxima capacidad expresiva.

En cuanto a la primera de ellas, en «Trébol» la recreación gongorina únicamente se da al explicitar el «pace estrellas». No nos sirve decir para justificar esta primera vía que Darío haya empleado recursos culteranistas en sus sonetos - hiperbatos, metáforas, perífrasis, aliteraciones (como si Góngora hubiera sido el inventor de los mismos)—, y, por lo que respecta al léxico gongorino empleado, es cierto que lo hay, por ejemplo, las palabras «ardiente», "armonía», «brillo», «diamante», «diente», «duplicó», «Fénix», «joya», «juego», «rompe», «sacro», son utilizadas por Góngora en sus poemas ${ }^{22}$; no obstante, también hay palabras que no aparecen en la lírica gongorina («augura», "poniente», «penumbra», «reluciente», «veste»), aunque parezcan ciertamente giros gongorinos (Entrambasaguas, 1975: 193; Quintián, 1974: 165). Son estos últimos términos cultismos del siglo XVII que podemos encontrar también en Lope, Quevedo y Calderón.

En cuanto a la segunda vía, cabe decir que esta es el resultado de una decisión de carácter estético e intelectual, una «elección, no sólo por moda, sino convencida, razonada, estéticamente preferible, de la lengua poética propuesta por Góngora» (Tenorio, 2013: 24). De manera que no podemos acusar a Darío de ser un gongorista avant la lettre, pues poco hay de Góngora en su poesía. Lo que podemos afirmar es que sí hay respeto por el vate cordobés. Respeto, mucho, y, sobre todo, comprensión de la intención estética de Góngora. No creemos que Darío pretendiese imitarla, sino únicamente rendir homenaje en estos sonetos al mejor pintor del Barroco español y al poeta más influyente del siglo XVII hispánico. ${ }^{23}$

\section{Conclusiones}

Como se ha podido comprobar, «Trébol» supone un sentido homenaje a dos grandes «monstruos de la naturaleza», realizado con virtuosismo y cuidado esfuerzo por parte de Darío. No resulta extraño, pues, que en 1927 Gerardo

22. Por cierto, también son palabras comunes en Lope de Vega.

23. Lo expresó acertadamente Antonio Carreira, quien a propósito de «Trébol» escribió: «Rubén Darío fue, con su "trébol" de sonetos de 1899 en homenaje a Góngora y Velázquez, el primer poeta moderno que, estimulado por la afección de algunos simbolistas franceses hacia el poeta "maldito" o proscrito, defiende la causa de Góngora aun sin haberlo leído en profundidad. Su ejemplo fue fructífero y desde entonces poetas y eruditos van a ir poco a poco prestando atención a Góngora.» (Carreira, 1986: 62) 
Diego incluyese estas composiciones darianas al final de la antología que preparó en honor a Góngora (Diego, 1979: 189-190).

Cargados de simbología y metáforas a la manera culterana —y no gongorina-, la combinación de elementos fónicos, así como la cuidada y consciente selección léxico-semántica, junto a los procedimientos y la atmósfera simbolista, estos sonetos bien merecen estar entre uno de los mejores homenajes de nuestras letras hispánicas, por mucho que algunos críticos hayan querido, desde su publicación, desprestigiarlos y ver en ellos errores y burdas imitaciones gongorinas, la mayoría de ellas infundadas.

Por otro lado, aunque el motivo que le impulsó a escribir estos versos no fuera nuevo —elección del retrato-, sí lo fue el procedimiento poético utilizado por Darío — poesía de la experiencia culturalista—; procedimiento que, como hemos visto, busca celebrar en los sonetos una experiencia del propio poeta nicaragüense que lo vincula a los dos artistas homenajeados por la calidad de sus obras. Una experiencia compartida con los lectores para que recreemos de modo simultáneo la vivencia que expresan los versos, sobre todo los del primer y el tercer soneto. Versos donde Darío, como en muchas de sus composiciones, muestra además su vasto imaginario cultural a través de imágenes culturales interpuestas, cuya lección clásica, como ha expresado acertadamente José Carlos Rovira, «está construida no externamente, no como referentes que se cierran en la recreación de motivos, sino en el uso de los mismos para las diferentes situaciones expresivas que pretende.» (Rovira, 2009: 130)

En conclusión, «Trébol» es un homenaje que no puede quedar solo en lo literario, sino que debe entenderse como un homenaje a la época dorada de la cultura española. Todo ello mediante la utilización de imágenes de dos periodos históricos y movimientos literarios anacrónicos, donde el intelectualismo reflexivo de Darío queda evidenciado y se afirma como criterio esencial en los poemas.

\section{Bibliografía citada}

ALARCÓN SIERRA, Rafael, «Valores simbolistas en la literatura española del primer tercio del siglo XX», en Anales de Literatura Española, Nº 15 (2002), pp. 71- 92.

Alonso, Dámaso, «Góngora y la literatura contemporánea», en Estudios y ensayos gongorinos, Madrid, Gredos, 1970, pp. 518-566.

ANDERSOn Imbert, Enrique, La originalidad de Rubén Darío, Buenos Aires, Centro Editor de América Latina, 1967.

BAUDELAIRE, Charles, Las flores del mal (ed. bilingüe de Alain Verjat y Luis Martínez de Merlo), Madrid, Cátedra, 2012. 
Bernabé, Mónica, «El otro y el mismo. Sujeto poético en Cantos de vida y esperanza», en Enrique Foffani (comp.), La protesta de los cisnes. Coloquio sobre Cantos de vida y esperanza, de Rubén Darío (1905-2005), Buenos Aires, Katatay, 2007, pp. 111- 119.

CARILlA, Emilio, «Góngora y la literatura contemporánea en Hispanoamérica», en Revista de Filología Española, XLIV (1961), pp. 237-282.

- «Góngora en la bibliografía argentina», en Revista de Filología Española, XLV (1962), pp. 19-30.

CARNERO, Guillermo, «La ruptura modernista», en Anales de Literatura Española, $\mathrm{N}^{\mathrm{o}} 15$ (2002), pp. 13-25.

- «Reflexiones egocéntricas I. Cuatro formas de culturalismo», en Poéticas y entrevistas. 1970-2007, Málaga: Centro Cultural Generación del 27, 2008, pp. 67-75.

CARREIRA, Antonio, «Introducción» a Luis de Góngora, Antología poética, Madrid, Editorial Castalia, pp. 25-66.

Cullell, Diana, La poesía de la experiencia española de finales del siglo XX al XXI, Madrid, Devenir Ensayo, 2010.

Darío, Rubén, Autobiografía. Oro de Mallorca (Int. de Antonio Piedra), Madrid, Mondadori, 1990.

- España contemporánea (pról. de Sergio Ramírez), Madrid, Alfaguara, 1998.

- Antología (ed. de Carmen Ruiz Barrionuevo), Madrid, Espasa Calpe, 1999.

- Cantos de vida y espranza (pról. y ed. de José Carlos Rovira), Madrid, Alianza Editorial, 2004.

- Poesías. Edición facsimilar y con variantes (ed. de Rossi de Fiori, I., et al.), México D. F., FCE, 2004.

- Obra poética (ed. de José Carlos Rovira, con la colaboración de Sergio Galindo), Madrid, Fundación José Antonio de Castro, 2011.

- Del símbolo a la realidad. Obra selecta, Barcelona, Real Academia Española/ Asociación de las Academias de la Lengua Española/ Alfaguara, 2016.

DiEgo, Gerardo (comp.), Antología poética en honor a Góngora, Madrid, Alianza, 1979.

DijK, Teun A. van, Some Aspects of Tex Gammars. A Study in Theoretical Linguistics and Poetics, La Haya, Mouton, 1972.

ENTRAmbASAgUAS, Joaquín de, «Góngora y Velázquez en Rubén Darío», en Estudios y ensayos sobre Góngora y el Barroco, Madrid, Editora Nacional, 1975, pp. 187-194.

FERnÁNDEZ, Teodosio, La poesía hispanoamericana (hasta final del Modernismo), Madrid, Taurus, 1989.

— «Rubén Darío y la gestación del lenguaje modernista», en T. Albaladejo, J. Blasco y R. de la Fuente (coords.), El Modernismo. Renovación de los lenguajes poéticos, Valladolid, Secretariado de Publicaciones, 1990. 
ForCadas, Alberto, «Más sobre el gongorismo de Rubén Darío», Papeles de Son Armadans, LXVI (1972), pp. 41-55.

- «Notas sobre la Galatea gongorina y la marquesa verlainiana en Rubén Darío», en La Torre, XXIV, 91-92 (1976), pp. 125-144.

García Berrio, Antonio y Teresa Hernández Fernández, Crítica literaria. Iniciación al estudio de la literatura, Madrid, Cátedra, 2004.

GARCÍA MARTínEZ, Luis Fernando, La ékfrasis en la poesía contemporánea española: de Ángel González a Encarnación Pisonero, Madrid, Devenir Ensayo, 2011.

GIL DE BIEDMA, Jaime, «El mérito de Espronceda», en Obras. Poesía y prosa, (ed. de Nicanor Vélez), Barcelona, Círculo de lectores/Galaxia Gutenberg, 2010, pp. 749-758.

GÓNGORA, Luis de, Antología poética (ed. de Antonio Carreira), Madrid, Editorial Castalia, 1986.

- Sonetos completos (ed. de Biruté Ciplijauskaité), Madrid, Editorial Castalia, 1992.

- Soledades (ed. de Robert Jammes), Madrid, Editorial Castalia, 1994.

- Fabula de Polifemo y Galatea (ed. de Jesús Ponce Cárdenas), Madrid, Cátedra, 2010.

JimÉNEZ, José Olivio, Diez años de poesía española. 1960-1970, Madrid, Ínsula, 1972.

LANGBAUM, Robert, Poesía de la experiencia. El monólogo dramático en la tradición literaria moderna, Granada, Comares, 1996.

MARTínEZ FERNÁNDEZ, José Enrique, La intertextualidad literaria, Madrid, Cátedra, 2001.

MARTOS, José Manuel, «Góngora, Velázquez y Rubén Darío: el diálogo imposible de "Trébol" (Cantos de vida y esperanza, Otros poemas, VII)», en Hispanic review, No 2 (1998), pp. 171-180.

MAYORAL, José Antonio, Figuras retóricas, Madrid, Síntesis, 1994.

Mejías Alonso, Almudena, «El soneto en Azul..., Prosas profanas y Cantos de vida y esperanza: una aproximación a la métrica de Rubén Darío», en Anales de literatura hispanoamericana, $\mathrm{N}^{\circ} 14$ (1985), pp. 237-250.

NeIRA, Julio y Javier PÉREz BAZO, Luis Cernuda en el exilio: lecturas de Las Nubes y Desolación de la Quimera, Toulouse, Presses Universitaires du Mirail, 2002.

PAZ, Octavio, «El caracol y la sirena», en Rubén Darío, Antología (ed. de Carmen Ruiz Barrionuevo), Madrid, Espasa Calpe, 1999, pp. 11- 58.

Petriconi, Helmuth, «Góngora und Darío», en Die Neuren Sprachen, XXXVI, 1927, pp. 261-272.

Platas TASEnde, Ana María, Diccionario de términos literarios, Madrid, Espasa Calpe, 2004.

Quevedo, Francisco de, Poesía varia (ed. de James O. Crosby), Madrid, Cátedra, 2005. 
QUintián, Andrés R., Cultura y Literatura españolas en Rubén Darío, Madrid, Gredos, 1974.

Roses, Joaquín, Góngora: soledades habitadas, Málaga, Servicio de Publicaciones de la Universidad de Málaga, 2007.

Rovira, José Carlos, «Prólogo» a Rubén Darío, Cantos de vida y esperanza, Madrid, Alianza Editorial, 2004, pp. 7-40.

- «La lección de Darío en la España de 1905: lo clásico como otro origen de la modernidad», en Cuadernos del CILHA, Vol. 10, N. 11 (2009), pp. 128-137.

— «Introducción» a Rubén Darío, Obra poética, Madrid, Fundación José Antonio de Castro, 2011, pp. 21-63.

— «El "clasicismo modernista" de Rubén Darío y la tradición española: su sistematización en Cantos de vida y esperanza», en Rubén Darío, Del símbolo a la realidad. Obra selecta, Barcelona, Real Academia Española/ Asociación de las Academias de la Lengua Española/ Alfaguara, 2016, pp. 305-336.

Ruiz Barrionuevo, Carmen, Rubén Darío, Madrid, Editorial Síntesis, 2002.

SAlinas, Pedro, La poesía de Rubén Darío. Ensayo sobre el tema y los temas del poeta, Barcelona, Seix Barral, 1975.

SENABRE, Ricardo, «El gongorismo de Rubén Darío», en Papeles de Son Armadans, XLVI (1967), pp. 267-284.

TENORIO, Martha Lilia, El gongorismo en Nueva España. Ensayo de restitución, México D. F., El Colegio de México, Centro de Estudios Lingüísticos y Literarios, 2013. 


\section{Anexo I}

I

De D. Luis de Argote y Góngora

a D. Diego de Silva Velázquez

Mientras el brillo de tu gloria augura ser en la eternidad sol sin poniente, fénix de viva luz, fénix ardiente, diamante parangón de la pintura,

de España está sobre la veste obscura tu nombre, como joya reluciente; rompe la Envidia el fatigado diente, y el Olvido lamenta su amargura.

Yo en equívoco altar, tú en sacro fuego, miro a través de mi penumbra el día en que el calor de tu amistad, don Diego,

jugando de la luz con la armonía, con la alma luz, de tu pincel el juego el alma duplicó de la faz mía.
II

De D. Diego de Silva VelázQuez

A D. Luis DE Góngora y ARGOTE

Alma de oro, fina voz de oro, al venir hacia mí, ¿por qué suspiras? Ya empieza el noble coro de las liras a preludiar el himno a tu decoro;

5 ya el misterioso son del noble coro calma el Centauro sus grotescas iras, y con nueva pasión que les inspiras tornan a amarse Angélica y Medoro.

A Teócrito y Poussin la Fama dote

10 con la corona de laurel supremo; 10 que en donde da Cervantes el Quijote

y yo las telas con mis luces gemo, para Don Luis de Góngora y Argote traerá una nueva palma Polifemo.

III

En tanto «pace estrellas» el Pegaso divino, y vela tu hipogrifo, Velázquez, la Fortuna, en los celestes parques al Cisne gongorino deshoja sus sutiles margaritas la Luna.

Tu castillo, Velázquez, se eleva en el camino

del Arte como torre que de águilas es cuna, y tu castillo, Góngora, se alza al azul cual una jaula de ruiseñores labrada en oro fino.

Gloriosa la península que abriga tal colonia. ¡Aquí bronce corintio y allá mármol de Jonia! Las rosas a Velázquez, y a Góngora claveles.

De ruiseñores y águilas se pueblan las encinas, y mientras pasa Angélica sonriendo a las Meninas, salen las nueve musas de un bosque de laureles. 